Abstract 014 Table 1 HIV infection according to patient demographics

\begin{tabular}{|c|c|c|c|}
\hline Variable & $\begin{array}{l}\% \text { (n) recent } \\
\text { HIV infection }\end{array}$ & $\begin{array}{l}\% \text { (n) longstanding } \\
\text { HIV infection }\end{array}$ & $\begin{array}{l}\text { Unadjusted RR of } \\
\text { being diagnosed with } \\
\text { recent infection ( } 95 \% \mathrm{CI})\end{array}$ \\
\hline Age (mean 35 years, SD 9.98, range $16-66$ years) & - & - & $0.98(0.96$ to 1.00$)$ \\
\hline MSM (vs heterosexual)* & $76.5(65)$ & $45.5(180)$ & $1.68(1.43$ to 1.97$)$ \\
\hline \multicolumn{4}{|l|}{ Previous STI† } \\
\hline Chlamydia trachomatis & $21.2(18)$ & $14.9(81)$ & $1.42(0.90$ to 2.24$)$ \\
\hline Syphilis & $8.2(7)$ & $7(38)$ & $1.18(0.54$ to 2.55$)$ \\
\hline Gonorrhoea & $16.5(14)$ & $10.5(57)$ & $1.57(0.92$ to 2.69$)$ \\
\hline Lymphogranuloma venereum (LGV) & $1.2(1)$ & $0.9(5)$ & $1.28(0.15$ to 10.8$)$ \\
\hline Any STI & $37.6(32)$ & $24.5(133)$ & $1.54(1.13$ to 2.10$)$ \\
\hline \multicolumn{4}{|c|}{ Visits in the year preceding date of HIV diagnosis/RITA test $\dagger$} \\
\hline$>2$ visits & $68(34)$ & $54.8(188)$ & $1.24(1.00$ to 1.54$)$ \\
\hline
\end{tabular}

${ }^{*} \mathrm{n}=481$.

tRecorded in the same GUM clinic.

łIncludes Chlamydia, syphilis, gonorrhoea, LGV.

visiting a sexual health clinic more than twice in the previous year were also more likely to be diagnosed at early stages of HIV infection.

Conclusions Important behavioural and demographic differences exist between individuals diagnosed with recent vs established HIV infections. Such differences must be considered when deriving incidence estimates among key at-risk groups. Further work to examine these trends among all RITA results, in particular the relationship with HIV testing patterns, is ongoing.

\section{PRIMARY HIV INFECTION: LACK OF KNOWLEDGE AMONG MEN WHO HAVE SEX WITH MEN (MSM)}

doi:10.1136/sextrans-2012-050601a.15

${ }^{1} \mathrm{~K}$ Conway, ${ }^{*} \mathrm{D}$ Jack, ${ }^{2} \mathrm{C}$ Dew, ${ }^{3} \mathrm{~S}$ Johnson, ${ }^{1} \mathrm{~V}$ Cooper, ${ }^{1} \mathrm{~L}$ Waters, ${ }^{1} \mathrm{M}$ Fisher. ${ }^{1}$ Royal Sussex County Hospital, Brighton, UK; ${ }^{2}$ National AIDS Trust; ${ }^{3}$ Gaydar

Introduction Primary HIV infection (PHI) is commonly symptomatic, offers an opportunity for early diagnosis and is important for individual health and preventing transmission. At risk populations should be aware of PHI symptoms.

Aim To ascertain PHI knowledge among UK MSM.

Methods Online anonymous survey conducted by the National AIDS Trust using the GaydarTM website between 31 March 2011 and 6 April 2011. Questions were asked about likelihood/nature of PHI symptoms and transmission risk. Data on recent HIV testing, HIV status and response to symptoms was collected. Analysis was done using $\chi^{2}$ tests.

Results 8561 men responded: $76 \%$ had tested for HIV (16\% positive), $21 \%$ were untested and 3\% did not disclose. 5159/8548 (60\%) believed PHI to be asymptomatic and 799/8548 (9\%) correctly answered that $70 \%-90 \%$ would have symptoms; HIV+ MSM were significantly more likely to be aware of this than HIV-/untested MSM $(14.9 \%$ vs $8.2 \%, \mathrm{p}<0.0001)$ and MSM who had tested were more likely to be aware than never testers $(10.2 \%$ vs $5.8 \%$, $\mathrm{p}<0.0001$ ). 2926/8267 (35.4\%) identified the fever/sore throat/rash triad as the most common presentation of PHI. MSM who had never HIV tested were less likely to correctly identify these symptoms than those who had $(29.3 \%$ vs $37.0 \%, p<0.0001) .2964 / 8450$ (35.1\%) believed it is hard to transmit HIV in early infection; the remainder recognised PHI as highly infectious. HIV+ MSM were more likely to recognise this than HIV-/untested MSM $(76.8 \%$ vs $62.5 \%, \mathrm{p}<0.0001)$ and untested MSM were less likely to recognise this than those who had tested $(60.4 \%$ vs $66 \%, \mathrm{p}<0.0001) .4220 /$ 6918 (61\%) of HIV-/untested MSM would seek medical advice if symptomatic; the remainder would ignore symptoms or await resolution. Of those who would seek advice $54.1 \%$ would attend GP/NHS walk-in centre and $34.6 \%$ would attend GU clinic or take community HIV test.

Discussion This survey illustrates a concerning lack of knowledge among MSM regarding PHI symptoms and the urgent need for ongoing health promotion and education.

\section{USE OF ONLINE ASSESSMENT TOOLS BY RISK TAKING MEN}

doi:10.1136/sextrans-2012-050601a.16

${ }^{1} \mathrm{P}$ Ward, ${ }^{1} \mathrm{~L}$ Power, ${ }^{2} \mathrm{~A}$ Nardone, ${ }^{2} \mathrm{~T}$ Hartney, ${ }^{2} \mathrm{~V}$ Delpech. ${ }^{1}$ Terrence Higgins Trust, London, UK; ${ }^{2}$ Health Protection Agency

Background Condom use by gay men has slipped since the 1990s. In late 2011 THT (as part of CHAPS) launched a condom campaign for younger men, promoting a web-based HIV risk assessment tool.

Methods The Clever Dick/Smart Arse campaign encouraged use of an online risk assessment tool with prize incentives. This gave an instant rating on sexual activity in the past year, with a detailed risk report on request. This covered behaviours affecting HIV risk including PEP, poppers, condoms, HIV disclosure, receptive or insertive modality, monogamy, treatment and viral load.

Results 7240 risk assessments were undertaken in 10 weeks of whom 1810 requested their full risk assessment ("Sexscore") and agreed to further contact. There were 101248 page views by over 17000 unique website visitors with average visit time of 3.03 min. Preliminary analysis of 4574 respondents shows high levels of risky behaviours. The majority were not in regular clinic contact while a third had never had a sexual health screen. $24 \%$ had never tested for HIV while $10 \%$ were knowingly $\mathrm{HIV}+$ (of whom $62 \%$ had undetectable VL throughout the year). Over half $(56 \%)$ had five or more sexual partners in the year. $53 \%$ of HIV + men and $51 \%$ of other men reported UAI with one or more partners and $59 \%$ of all participants discussed serostatus before sex.

Conclusion Gay men will engage about risk taking if feedback is instant and anonymous, including those never in contact with sexual health services. Men reporting risk behaviours can be targeted for subsequent interventions. 